УДК 544.45 .452 .2

\title{
О МЕХАНИЗМЕ ХИМИЧЕСКОГО СВЯЗЫВАНИЯ АЗОТА ВОЗДУХА В УСЛОВИЯХ ТЕПЛОВОГО ВЗРЫВА СМЕСЕЙ НАНОПОРОШКА АЛЮМИНИЯ С ОКСИДОМ ТАНТАЛА
}

\author{
Чудинова Александра Олеговна',
} chudinova.1509@mail.ru

\author{
Ильин Александр Петрович', \\ ilyin@mail.ru
}

\author{
Роот Людмила Олеговна', \\ tolbanova@mail.ru
}

\section{Мостовщиков Андрей Владимирович', avmost@tpu.ru}

\section{Спесивцева Софья Викторовна', ivakhnyuk-sofya@mail.ru}

\author{
Джин Чун Ким², \\ jckimpm|@ulsan.ac.kr \\ 1 Национальный исследовательский Томский политехнический университет, \\ Россия, 634050, г. Томск, пр. Ленина, 30. \\ 2 Ульсанский Университет, \\ Республика Корея, 680-749, г. Ульсан.
}

Актуальность исследования. Предлагаемая новая технология получения тугоплавких нитридов имеет ряд преимуществ: низкие энергозатраты, отсутствие необходимости в сложном оборудовании, для получения нитридов используется азот воздуха, процесс синтеза осуществляется при атмосферном давлении.

Цель исследования: экспериментально определить составы продуктов сгорания смесей нанопорошка алюминия и пентаоксида тантала в воздухе и в жидком азоте.

объект: продукты синтеза нитрид тантала, полученные сжиганием в воздухе смесей нанопорошка алюминия с пентаоксидом тантала.

Методы: рентгенофазовый анализ (дифрактометр Дифрей-401), дифференциальный термический анализ (ДтА) (термоанализатор Q600 SDT, фирма Instrument). На основании результатов ДТА были рассчитаны четыре параметра активности смесей: тем-

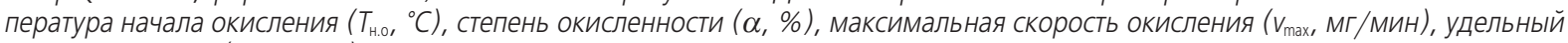
тепловой эффект ( $\Delta H$, Дж/г). Рентгенофазовый анализ с использованием дифрактометра «Дифрей-401», излучение рентгеновской трубки $\mathrm{Fe}_{\mathrm{K}_{\alpha}}=0,193 \mathrm{Hм}$

Результаты. Определены параметры активности смесей нанопорошка алюминия с пентаоксидом тантала. Установлено, что температура начала окисления смесей равна или превышает $420^{\circ} \mathrm{C}$, т. е. смеси не пирофорны. Процесс горения, инициированный открытым пламенем, протекал в две стадии: при 600-900 и при 2200-2400 ㄷ. Изучены продукты сгорания смесей нанопорошка алюминия с пентаоксидом тантала в воздухе и в жидком азоте. Впервые экспериментально показано, что при горении нанопорошка алюминия в воздухе алюминий восстанавливает пентаоксид тантала, который взаимодействует с азотом воздуха, образуя кристаллический нитрид тантала $\mathrm{Ta}_{2} N$. Максимальный выход нитрида тантала при сгорании в воздухе с образованием кристаллической фазы Та 2 N составлял 54 отн. \%. Согласно РФА, также впервые в продуктах сгорания в жидком азоте смеси нанопорошка алюминия с пентаоксидом тантала обнаружены кристаллические фазы $\alpha$ - и $\beta$-тантала. В то же время нитрид тантала не обнаружен в продуктах сгорания образца в жидком азоте. Стабилизация металлической фазы тантала при взаимодействии нанопорошка алюминия с пентаоксидом тантала в условиях теплового взрыва подтверждает ранее сформулированное предположение о механизме образования тугоплавких нитридов. На первой стадии алюминий восстанавливает тантал до металла, и в условиях теплового взрыва и дезактивации кислорода (нетеплового процесса перехода триплетного кислорода в синглетный) происходит взаимодействие восстановленного металла с азотом.

\section{Ключевые слова:}

Нитрид тантала, тепловой взрыв, нанопорошок, алюминий, газ азот, жидкий азот, тантал, пентаоксид тантала, термодинамика, кислород, синтез сжиганием.

\section{Введение}

Долгое время (с 40-х гг. прошлого века по настоящее время) считалось, что металлы (тантал, алюминий, титан, ниобий и другие) при сгорании в воздухе образуют только оксиды, а азот является химически инертным веществом $[1,2]$. Согласно эксперимен- тальным данным, новым основным конечным продуктом сгорания порошкообразного алюминия в воздухе является нитрид алюминия [3].

Возможность образования нитридов допускалась только в качестве промежуточных веществ, обязательно доокисляющихся до оксидов, кроме 
того, согласно термодинамическим расчетам, окисление алюминия в воздухе должно протекать до оксида [4, 5]. Тем не менее химическое связывание азота воздуха известно и происходит при сгорании порошков ниобия и тантала с образованием нитрида тантала [6].

При горении в воздухе нанопорошка алюминия $(\mathrm{H \Pi} \mathrm{Al)} \mathrm{с} \mathrm{оксидами} \mathrm{тантала,} \mathrm{ниобия} \mathrm{и} \mathrm{др.} \mathrm{образу-}$ ются и стабилизируются соответствующие нитриды [7-11]. В то же время процессы при горении и распределении элементов в продуктах сгорания практически не изучены: в процессе формирования кристаллических фаз происходит неравномерное распределение азота. Однородность продуктов сгорания достигается последующим их дезагрегированием и измельчением. Таким образом, перспективным способом химического связывания азота воздуха и получения тугоплавких нитридов тантала [12], ниобия, титана, циркония и др. является синтез сжиганием в воздухе нанопорошка алюминия с соответствующими оксидами.

Предполагаемая технология получения тугоплавких нитридов имеет ряд преимуществ: низкие энергозатраты, отсутствие необходимости в сложном оборудовании [13-18], наличие плавно меняющихся слоев между различными кристаллическими фазами. Процесс синтеза происходит в воздухе при атмосферном давлении. Для осуществления синтеза необходим только кратковременный локальный нагрев исходной шихты, затем процесс протекает самопроизвольно.
Цель настоящей работы экспериментально определить составы продуктов сгорания смесей нанопорошка алюминия и пентаоксида тантала в воздухе и в жидком азоте.

\section{Методики экспериментов}

\section{и характеристики объектов исследования}

Нанопорошок алюминия был получен с использованием опытно-промышленной установки «УДП-4Г», изготовленной в Научно-исследовательском институте высоких напряжений ТПУ [19]. Схема установки приведена на рис. 1.

В качестве объекта исследования выбрана смесь $\mathrm{HП} \mathrm{Al} \mathrm{с} \mathrm{пентаоксидом} \mathrm{тантала} \mathrm{Ta}_{2} \mathrm{O}_{5}$ в мольном $4: 1$ или в массовом соотношении $0,79: 3,21$.

Смешивание нанопорошка алюминия с пентаоксидом тантала проводили механическим способом - растиранием смесей на кальке. Из полученной смеси формировали цилиндрический образец высотой 6-8 мм и диаметром 30 мм. Образец формировали в стальной пресс-форме.

Величину пористости регулировали давлением прессования до 3 МПа. В результате был получен высокопористый газопроницаемый образец, сохраняющий форму в процессе горения. Масса компактированного образца составляла 4 г. Образец зажигали в воздухе и сбрасывали в жидкий азот [20-25]. Фотографии процесса горения образца представлены на рис. 2.

Горение [14-26] протекало в две стадии. Первая стадия происходила в воздухе и представляла

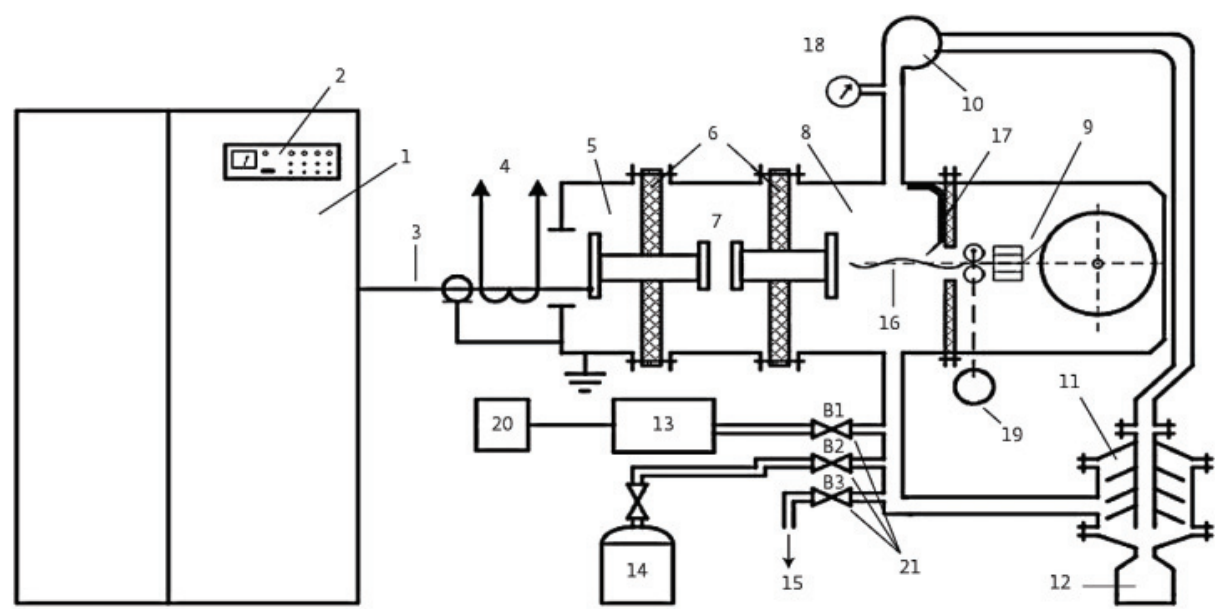

Рис. 1. Схема установки УДП-4Г для получения нанопорошка алюминия по методу электрического взрыва проводника (ЭВП): 1 - блок питания; 2 - пульт управления; 3 - высоковольтные кабели; 4 - токовый шунт; 5 - камера высоковольтного ввода; 6 - проходные изоляторы; 7 - разрядник; 8 - взрывная камера; 9 - механизм подачи проводника; 10 - вентилятор; 11 - фильтр-уловитель нанопорошка; 12 - сборник нанопорошка; 13 - форвакуумный насос; 14 - баллон с газом; 15 - трубопровод для сброса газа в вытяжную вентиляцию; 16 - взрывающийся проводник; 17 - заземленный электрод; 18 - вакуумметр; 19 - двигатель механизма подачи проводника; 20 - пульт управления форвакуумным насосом; 21 газовые краны

Fig. 1. Scheme of the UDP-4G for production of aluminum nanopowder by the method of wire electrical explosion (WEE): 1 is the power supply; 2 is the control panel; 3 are the high-voltage cables; 4 is the current shunt; 5 is the high-voltage input chamber; 6 are the bushing insulators; 7 is the discharger; 8 is the explosion chamber; 9 is the feeder mechanism; 10 is the fan; 11 is the filter-trap of nanopowder; 12 is the nanopowder chamber; 13 is the fore-vacuum pump; 14 is the cylinder with gas; 15 is the pipeline for venting gas into the exhaust ventilation; 16 is the exploding conductor; 17 is the grounded electrode; 18 is the vacuum meter; 19 is the feeder mechanism motor; 20 is the control panel for vacuum pump; 21 are the gas valves 
собой распространение волны горения по боковой поверхности с образованием сплошного горящего кольца и перемещением фронта горения вглубь образца.

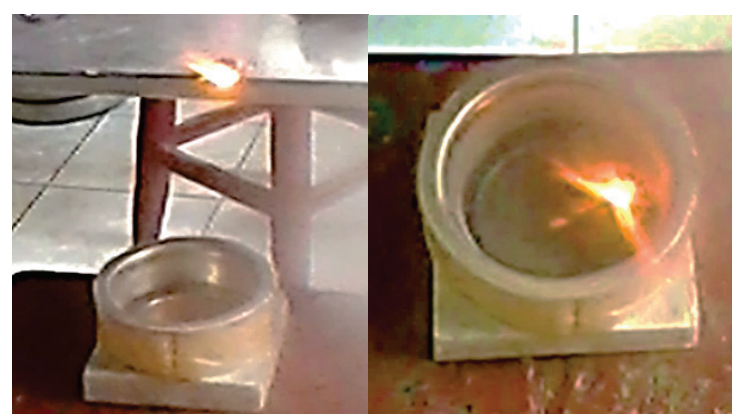

Pис. 2. Фотографии процесса зажигания и горения таблеток из смеси нанопорошка алюминия с пентаоксидом тантала: инициирование горения в воздухе и горение в жидком азоте

Fig. 2. Photos of combustion initiate and tablet burning of aluminum nanopowder and tantalum pentaoxide in air and combustion in liquid nitrogen

Затем образец сбрасывали в жидкий азот, и горение переходило в следующую стадию, в результате которой достигалась максимальная температура. Самопроизвольное быстрое увеличение температуры сопровождается увеличением интенсивности свечения и соответствует тепловому взрыву. После достижения тепловыделения и максимальной температуры интенсивность излучения снижалась: продукты сгорания остывали в среде жидкого азота.

\section{Результаты экспериментов}

После инициирования процесс горения нанопорошка протекал в режиме тления при $600-900{ }^{\circ} \mathrm{C}$ с последующим перемещением фронта горения вглубь образца. Затем горение переходило во вторую стадию уже в жидком азоте. Вторая стадия сопровождалась резким увеличением интенсивности свечения. Уменьшение интенсивности свечения образца свидетельствовало об охлаждении образца. Полученные спеки дезагрегировали и просеивали через сито с размером ячеек 63 мкм.

Для изучения термической устойчивости в воздухе нанопорошка алюминия и его смесей с пентаоксидом тантала использовали дифференциальный термический анализ.

Дифференциальный термический анализ использовали (рис. 3) для оценки реакционной способности исходного нанопорошка алюминия и исследуемых смесей, а также были рассчитаны четыре параметра их химической активности (табл. 1) [27].

Все приготовленные смеси имели температуру начала окисления выше $400{ }^{\circ} \mathrm{C}$. Скорость окисления максимальна для образца № 3: она мало отличалась от скорости окисления образца № 4 , но в 1,5 раза выше, чем для образца № 2.
Скорость окисления минимальна для образца без добавок. Таким образом, добавка пентаоксида тантала оказывает каталитическое влияние на горение нанопорошка алюминия. Степень окисленности смесей возрастает с 53,7 до 88,9 \% с увеличением содержания нанопорошка алюминия.

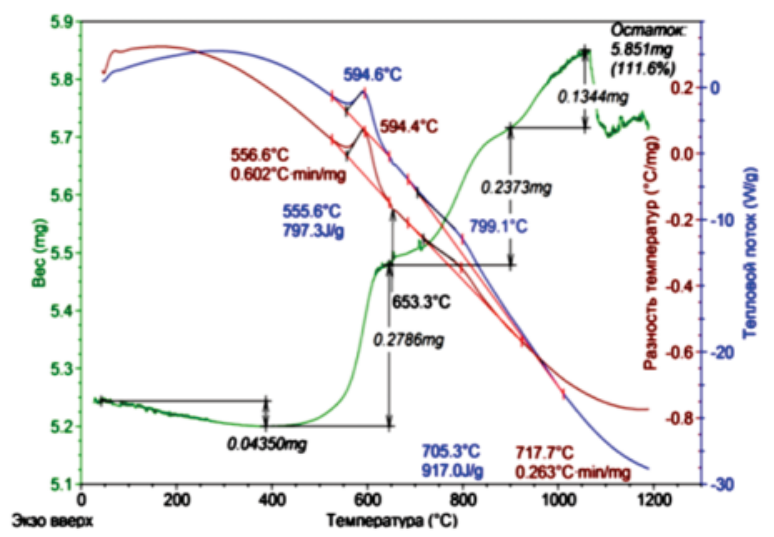

Рис. 3. Термограмма смеси нанопорошка алюминия с порошком пентаоксида тантала с массовым соотношением НП Al: $\mathrm{Ta}_{2} \mathrm{O}_{5}=4: 1$ (атмосфера - воздух, скорость нагрева $10^{\circ} \mathrm{C}$, вес $\left.-5,851 \mathrm{Mr}\right)$

Fig. 3. Thermogram of aluminum nanopowder and tantalum pentaoxide mixture with mass ratio NPAl: $\mathrm{Ta}_{2} \mathrm{O}_{5}=4: 1$ (air, heating rate $10^{\circ} \mathrm{C} / \mathrm{min}$, sample weight is $5,851 \mathrm{mg}$ )

Таблица 1. Параметры активности смесей нанопорошка алюминия с пентаоксидом тантала

Table 1. Activity parameters of aluminum nanopowder and tantalum pentaoxide mixtures

\begin{tabular}{|c|c|c|c|c|c|c|}
\hline \multirow{2}{*}{ 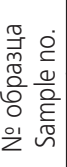 } & \multicolumn{2}{|c|}{$\begin{array}{l}\text { Состав образца, мас. частей } \\
\text { Composition sample, wt. parts }\end{array}$} & \multirow{2}{*}{ 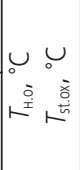 } & \multirow{2}{*}{ ơ } & \multirow{2}{*}{ 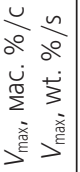 } & \multirow{2}{*}{ 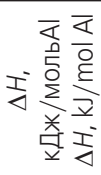 } \\
\hline & $\begin{array}{l}\mathrm{H} \Pi \mathrm{Al}, \Gamma \\
\text { Al NP, g }\end{array}$ & $\mathrm{Ta}_{2} \mathrm{O}_{5},\ulcorner/ g$ & & & & \\
\hline 0 & 4,00 & 0,00 & 445 & 53,7 & 0,025 & 6,7 \\
\hline 1 & 0,44 & 3,57 & 450 & 88,8 & 0,037 & 0,868 \\
\hline 2 & 0,62 & 3,38 & 420 & 88,8 & 0,029 & 1,466 \\
\hline 3 & 0,79 & 3,21 & 420 & 89,1 & 0,040 & 1,714 \\
\hline 4 & 0,93 & 3,06 & 510 & 88,9 & 0,038 & 2,235 \\
\hline
\end{tabular}

Тепловой эффект минимален для образца № 1 и увеличивается с 1521,5 до 6750 Дж/г. Тепловой эффект сгорания смеси нанопорошка алюминия с пентаоксидом тантала возрастает с увеличением содержания нанопорошка алюминия.

Для определения фазового состава продуктов сгорания использовали метод рентгенофазового анализа [19]. На рис. 4 представлена рентгенограмма продуктов сгорания в воздухе образца исходной смеси, для которого выход нитрида тантала максимальный (54 отн. \%).

Согласно рентгенофазовому анализу, в состав конечных продуктов сгорания смеси образца 3 входят: $\mathrm{Ta}_{2} \mathrm{~N}, \mathrm{Al}_{2} \mathrm{O}_{3}$ и невосстановленный $\mathrm{Ta}_{2} \mathrm{O}_{5}$. Из рентгенограммы следует, что нитриду тантала соответствует рефлекс100 \% интенсивности. 


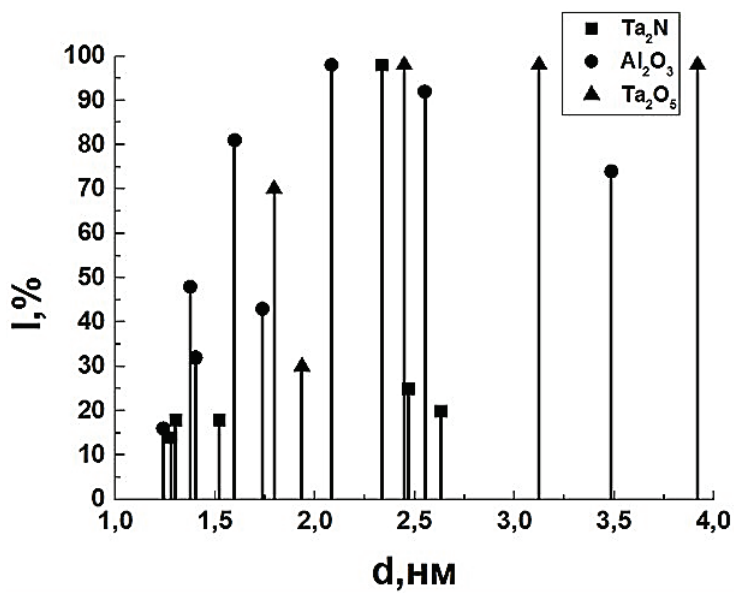

Рис. 4. Рентгенограмма продуктов сгорания в воздухе смеси нанопорошка алюминия с пентаоксидом тантала (массовое соотношение $\mathrm{H}$ П Al: $\mathrm{Ta}_{2} \mathrm{O}_{5}=4: 1$ )

Fig. 4. X-ray diagram of combustion products of tantalum pentaoxide and aluminum nanopowder mixture in air (NPA): $\left.\mathrm{Ta}_{2} \mathrm{O}_{5}=4: 1\right)$

Таблица 2. Состав продуктов сгорания смесей нанопорошка алюминия с пентаоксидом тантала по данным рентгенофазового анализа

Table 2. Composition of combustion products of mixtures of aluminum nanopowder with tantalum pentoxide according to $X$-ray analysis

\begin{tabular}{|c|c|c|c|}
\hline $\begin{array}{c}\text { Состав образца } \\
\left(\mathrm{H} \Pi \text { Al: } \mathrm{Ta}_{2} \mathrm{O}_{5}\right)\end{array}$ & \multicolumn{3}{|c|}{$\begin{array}{c}\text { Интенсивность } 100 \% \text { рефлекса фазы } \\
\text { Intensity of the } 100 \% \text { phase reflex }\end{array}$} \\
\cline { 2 - 4 } $\begin{array}{c}\text { Sample composition } \\
\left.\text { (NP Al: } \mathrm{Ta}_{2} \mathrm{O}_{5}\right)\end{array}$ & $\mathrm{Ta}_{2} \mathrm{~N}$ & $\mathrm{Al}_{2} \mathrm{O}_{3}$ & AlTaO \\
\hline$(2: 1)$ & 22,5 & 1,04 & 65,3 \\
\hline$(3: 1)$ & 28,5 & 8,00 & 22,7 \\
\hline$(4: 1)$ & 54,0 & 11,00 & - \\
\hline$(5: 1)$ & 52,3 & 6,50 & 7,50 \\
\hline
\end{tabular}

Выход нитрида тантала $\mathrm{Ta}_{2} \mathrm{~N}$ максимален и составляет 54 отн. \%, при мольном соотношении,

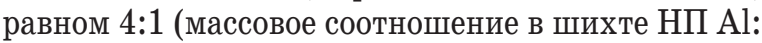
$\left.\mathrm{Ta}_{2} \mathrm{O}_{5}=0,79: 3,21\right)$.

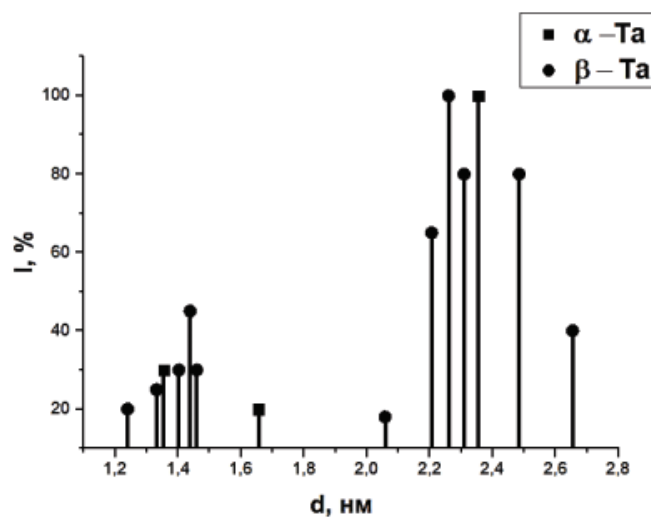

На рис. 5 приведена рентгенограмма продуктов сгорания смеси нанопорошка алюминия с пентаоксидом тантала в жидком азоте.

Рентгенограмма нитрида тантала в продуктах совпадает со штрих-диаграммой, взятой из картотеки PDF-260985, которая представлена на рис. 5. Согласно РФА, в продуктах сгорания в жидком азоте смеси нанопорошка алюминия с пентаоксидом тантала обнаружены кристаллические фазы $\alpha$ - и $\beta$-тантала (рис. 5 ), но нитрид тантала в продуктах отсутствовал.

Из рентгенограммы (рис. 5) следует, что $\alpha$-Та соответствует рефлекс $100 \%$ интенсивности, а в перерасчете на содержание $\alpha$-Та составляет 89,2 отн. \% , а содержание кристаллической фазы $\beta$-Та равно 10,7 отн. $\%$.

\section{Заключение}

Результаты исследований показали, что с увеличением содержания (табл. 2) исходного нанопорошка алюминия содержание нитрида тантала в продуктах сгорания увеличивалось и выход достигал 54 отн. \% . При сжигании смеси нанопорошка алюминия и пентаоксида тантала в жидком азоте стабилизировались две фазы металлического тантала - $\alpha$ - и $\beta$-разы. Нитрид тантала при сжигании смеси в жидком азоте не образовался из-за недостаточной температуры при горении.

Стабилизация металлической фазы тантала при взаимодействии нанопорошка алюминия с пентаоксидом тантала в условиях теплового взрыва подтверждает ранее сформулированное предположение о механизме образования тугоплавких нитридов. На первой стадии [27] алюминий восстанавливает оксид тантала до металла: в условиях теплового взрыва в воздухе и дезактивации кислорода [2] происходит взаимодействие восстановленного металла с азотом.

\section{Выводы}

1. Экспериментально установлено, что максимальный выход нитрида тантала в продуктах

Рис. 5. Рентгенограмма продуктов сгорания в жидком азоте смеси нанопорошка алюминия с пентаоксидом тантала (массовое соотношение НП Al: $\left.\mathrm{Ta}_{2} \mathrm{O}_{5}=4: 1\right)$ и штрих-диаграмма $\mathrm{TA}_{2} \mathrm{~N}$ (карточка PDF-260985)

Fig. 5. X-ray diagram of combustion products of tantalum pentaoxide and aluminum nanopowder mixture in nitrogen liquid (Al NP: $\left.\mathrm{Ta}_{2} \mathrm{O}_{5}=4: 1\right)$ and $X$-ray analyses of diagram of $\mathrm{Ta}_{2} \mathrm{~N}$ (card PDF-260985) 
сгорания смесей нанопорошка алюминия с пентаоксидом тантала наблюдается в образце с исходным соотношением $\mathrm{Al}: \mathrm{Ta}_{2} \mathrm{O}_{5}$, равным $4: 1$ $(0,79: 3,21)$, табл. 1. При этом содержание нитрида тантала, согласно рентгенофазовому анализу, достигало 54 отн. \% .

2. Установлено, что после сгорания в воздухе смесей нанопорошка алюминия с пентаоксидом тантала в продуктах сгорания содержится нитрид - $\mathrm{Ta}_{2} \mathrm{~N}$, который образуется при взаимодействии с азотом воздуха в присутствии дезактивированного кислорода

\section{СПИСОК ЛИТЕРАТУРЫ}

1. Beckstead M.W.A. Summary of aluminum combustion. RTO/VK Special Course on «Internal aerodynamics in Solid Rocket Propulsion». Report № RTOENO23, 2002. - 45 p.

2. Ильин А.П., Роот Л.О. Новый механизм высокотемпературного химического связывания азота воздуха // Фундаментальные исследования. - 2013. - № 6-6. - С. 1377-1381.

3. 0 влиянии азота на горение алюминия / В.М. Боборыкин, В.М. Гремячкин, А.Г. Истратов и др. // Физика горения и взрыва. - 1983. - № 3. - С. 22-29.

4. A facile synthesis of boron nitride nanosheets and their potential application in dye adsorption / Xiaobo Wanga, Yanfei Yanga, Guodong Jianga, Zewei Yuanc, Songdong Yuana // Diamond \& Related Materials. - 2018. - № 81. - P. 89-95.

5. Gromov A.A., Teipel U. Metal Nanopowders: Production, Characterization and Energetic Application. - Weinheim: Wiley-VCH, 2014. $-440 \mathrm{p}$.

6. Nobuzo Terao. Structure des Nitrures de Niobium // Jap. J. of applied physics. - 1965. - V. 64. - № 5. - P. 353-367.

7. Самсонов Г.В. Нитриды. - Киев: Наукова думка, 1969. - 377 с.

8. Самсонов Г.В. Химия и физика нитридов. - Киев: Наукова думка, 1968. - 174 с.

9. Тот Л. Карбиды и нитриды переходных металлов. - М.: Мир, 1974. $-294 \mathrm{c}$

10. Facile synthesis of powder-based processing of porous aluminum nitride / Kyungju Nam, Kicheol Hong, Hyeji Park, Heeman Choe // Journal of the European Ceramic Society. - April 2018. - V. 38. № 4. - P. 1164-1169.

11. Химия синтеза сжиганием / пер. с яп. / под ред. М. Коидзуми. - М.: Мир, 1998. - 247 с.

12. Low-temperature synthesis of tantalum carbide by facile one-pot reaction / Jinming Jiang, Song Wang, Wei Li, Zhaohui Chen // Ceramics International. - 2016. - V. 42. - № 6. - P. 7118-7124.

13. Schweiter C., Schmidt R. Physical Mechanisms of Generation and Deactivation of Singlet Oxygen // Chemical Review. - 2003. V. 103 (5). - P. 1685-1787.

14. Harneet Kaur Sidana, Rameez Ahmad Mir, Pandey 0.P. Synthesis of molybdenum nitride $\left(\mathrm{Mo}_{2} \mathrm{~N}\right)$ nanoflakes via in-situ reduction-nitridation // Journal of Alloys and Compounds. - 2018. № 736 . - P. 255-265.

15. Low-temperature direct synthesis of mesoporous vanadium nitrides for electrochemical capacitors / Hae-Min Lee, Gyoung Hwa Jeong, Sang-Wook Kim, Chang-Koo Kim // Applied Surface Science. - 2017. - № 400. - P. 194-199.
(2200-2400 $\left.{ }^{\circ} \mathrm{C}\right)$ с участием алюминия как восстановителя.

3. Определен фазовый состав продуктов сгорания: согласно рентгенофазовому анализу, в состав продуктов сгорания в воздухе смесей входят: $\mathrm{Ta}_{2} \mathrm{~N}, \mathrm{Al}_{2} \mathrm{O}_{3}, \mathrm{AlTaO}_{4}$.

4. Экспериментально показано, что при сгорании в жидком азоте смеси нанопорошка алюминия с пентаоксидом тантала в качестве конечного продукта стабилизируется металлический тантал.

Работа выполнена при поддержке Государственного задания «Наука», проект № 11.1928.2017/4.6.

16. Thobeka Kente, Sabelo Dalton Mhlanga. Gallium nitride nanostructures: Synthesis, characterization and applications // Journal of Crystal Growth. - 2016. - № 444. - P. 55-72.

17. Ковба Л.М., Трунов В.К. Рентгенофазовый анализ. - М.: МГУ, 1976. -232 c

18. Zarko V.E., Gromov A.A. Energetic nanomaterials: Synthesis, Characterization and Application. - Weincheim: Wiley-VCH, 2016. $-374 \mathrm{p}$.

19. Molten salt synthesis of tetragonal carbon nitride hollow tubes and their application for removal of pollutants from wastewater / Liang Tiana, Junyi Lia, Feng Lianga, Junkai Wanga, Saisai Lia, Haijun Zhanga, Shaowei Zhang // Applied Catalysis B: Environmental. - 2018. - № 225. - P. 307-313.

20. Aluminium nitride cubic modifications synthesis methods and its features. Review / V.S. Kudyakova, R.A. Shishkin, A.A. Elagin, M.V. Baranov, A.R. Beketov // Journal of the European Ceramic Society. - 2017. - № 37. - P. 1143-1156.

21. An atmospheric pressure microplasma process for continuous synthesis of titanium nitride nanoparticles / Liang liang Lin, S.A. Starostin, Qi Wanga, V. Hessel // Chemical Engineering Journal. - 2017. - № 321. - P. 447-457.

22. Synthesis of TiN nanostructures by $\mathrm{Mg}$-assisted nitriding $\mathrm{TiO}_{2}$ in $\mathrm{N}_{2}$ for lithium ion storage / Huimin Shi, Hang Zhang, Zhi Chena, Tao Wang, Lei Wang, Wei Zeng, Guanhua Zhang, Huigao Duan // Chemical Engineering Journal. - 2018. - № 336. - P. 12-19.

23. Synthesis of boron nitride nanostructures from catalyst of iron compounds via thermal chemical vapor deposition technique / W.M. da Silva, H. Ribeiro, T.H. Ferreira, L.0. Ladeira, E.M.B. Sousa // Physica E. - 2017. - № 89. - P. 177-182.

24. Facile synthesis of powder-based processing of porous aluminum nitride / Kyungju Nam, Kicheol Hong, Hyeji Park, Heeman Choe // Journal of the European Ceramic Society. - April 2018. - V. 38. Iss. 4. - P. 1164-1169.

25. Ognjanovic S.M., Winterer M. Optimizing particle characteristics of nanocrystalline aluminum nitride // Powder Technology. 15 February 2018. - V. 326. - P. 488-497.

26. Уэндландт У. Термические методы анализа. - М.: Мир, 1978. $218 \mathrm{c.}$

27. Горение нанопорошков металлов / А.А. Громов, Т.А. Хабас, А.П. Ильин и др. / под. ред. А.А. Громова. - Томск: Дельтаплан, 2008. - 382 с.

Поступила 18.06.2018 г. 


\section{Информация об авторах}

Чудинова A.O., аспирант отделения естественных наук Школы базового инженерного образования Национального исследовательского Томского политехнического университета.

Ильин А.П., доктор физико-математических наук, профессор отделения естественных наук Школы базового инженерного образования Национального исследовательского Томского политехнического университета.

Poom Л.O., кандидат технических наук, доцент отделения естественных наук Школы базового инженерного образования Национального исследовательского Томского политехнического университета.

Мостовщиков A.B., кандидат технических наук, старший научный сотрудник научно-исследовательской лаборатории СВЧ-технологий Инженерной школы ядерных технологий Национального исследовательского Томского политехнического университета.

Сnесивцева C.B., магистр отделения естественных наук Школы базового инженерного образования Национального исследовательского Томского политехнического университета.

Джин Чун Ким, доктор технических наук, профессор Школы материаловедения и машиностроения Ульсанского Университета. 


\section{ON AIR NITROGEN CHEMICAL BONDING IN HEAT EXPLOSION OF ALUMINUM NANOPOWDER AND TANTALUM OXIDE MIXTURES}

Alexandra 0. Chudinova',
chudinova.1509@mail.ru

Alexander P. llyin',

ilyin@mail.ru

Lyudmila 0. Root',

tolbanova@mail.ru

Andrey V. Mostovshchikov', avmost@tpu.ru

Sofia V. Spesivtseva',

ivakhnyuk-sofya@mail.ru

Jin Chun Kim²,

jckimpm|@ulsan.ac.kr

1 National Research Tomsk Polytechnic University,

30, Lenin avenue, Tomsk, 634050, Russia.

2 University of Ulsan,

Daehak-ro 102, Nam-gu, Ulsan, 680-749, South Korea.

The relevance of the research. The new proposed technology for obtaining refractory nitrides has several advantages: low energy consumption, no need for complex equipment, nitrogen is used to produce nitrides, synthesis is carried out at atmospheric pressure.

The main aim of the research is to determine experimentally the composition of combustion products of aluminum nanopowder and tantalum pentoxide mixtures in air and in liquid nitrogen.

Object: tantalum nitride synthesis product obtained by burning the aluminum nanopowder mixture with tantalum pentoxide in air. Methodsh: $x$-ray analysis (diffractometer Difrey-401), differential thermal analysis (DTA) (thermoanalyzer SDT Q600 Instrument company). According to the results of the DTA the authors have calculated four parameters of activity of the mixtures: oxidation onset temperature $\left(T_{\text {st.ox }},{ }^{\circ} \mathrm{C}\right)$, oxidation level $(\alpha, \%)$, maximal oxidation rate $\left(v_{\max }, \mathrm{mg} / \mathrm{min}\right)$, specific thermal effect $(\Delta H, \mathrm{~J} / \mathrm{g})$.

Results. The authors determined the parameters of activity of aluminum nanopowder with tantalum pentoxide mixtures. It is revealed that along with nitride and aluminum oxide in the products a crystalline phase of metallic tantalum is formed. The maximum yield of tantalum was $54 \mathrm{rel}$. \%. It was shown experimentally that at aluminum nanopowder combustion in air, aluminum recovers tantalum pentoxide, which interacts with air nitrogen to form crystalline $T_{2} N$ tantalum nitride. According to $X$-ray, in the combustion products of a mixture of aluminum nanopowder with tantalum pentoxide, the crystalline phases of $\alpha$ - and $\beta$-tantalum are found. At the same time, tantalum nitride was not detected when the sample was burned in liquid nitrogen.

\section{Key words:}

Tantalum nitride, thermal explosion, nanopowder, aluminum, gas nitrogen, liquid nitrogen, tantalum, tantalum pentoxide, thermodynamics, oxygen, synthesis by combustion.

The research was supported by the State task «Nauka», project no. 11.1928.2017/4.6.

\section{REFERENCES}

1. Beckstead M.W.A. Summary of aluminum combustion. RTO/VK Special Course on «Internal aerodynamics in Solid Rocket Propulsion». Report no. RTOENO23, 2002. 45 p.

2. Ilin A.P., Root L.0. Novy mekhanizm vysokotemperaturnogo khimicheskogo svyazyvaniya azota vozdukha [New mechanism of high-temperature chemical bonding of air nitrogen]. Fundamentalnye issledovaniya, 2013, no. 6-6, pp. 1377-1381.

3. Boborykin V.M., Gremyachkin V.M., Istratov A.G. 0 vliyanii azota na gorenie alyuminiya [Nitrogen impact on aluminum combustion]. Fizika goreniya i vzryva, 1983, no. 3, pp. 22-29.

4. Xiaobo Wanga, Yanfei Yanga, Guodong Jianga, Zewei Yuanc, Songdong Yuana. A facile synthesis of boron nitride nanosheets and their potential application in dye adsorption. Diamond \& $R e$ lated Materials, 2018, no. 81, pp. 89-95.
5. Gromov A.A., Teipel U. Metal Nanopowders: Production, Characterization and Energetic Application. Wiley-VCH, Weincheim, $2014.440 \mathrm{p}$.

6. Nobuzo Terao. Structure des Nitrures de Niobium. Jap. J. of applied physics, 1965 , vol. 64, no. 5, pp. 353-367.

7. Samsonov G.V. Nitridy [Nitrides]. Kiev, Naukova dumka Publ., 1969. $390 \mathrm{p}$.

8. Samsonov G.V. Khimiya i fizika nitridov [Chemistry and physics of nitrides]. Kiev, Naukova dumka, 1968. 174 p.

9. Thoht L. Karbidy i nitridy perekhodnykh metallov [Carbides and nitrides of transition metals]. Moscow, Mir Publ., 1974. 294 p.

10. Kyungju Nam, Kicheol Hong, Hyeji Park, Heeman Choe. Facile synthesis of powder-based processing of porous aluminum nitride. Journal of the European Ceramic Society, April 2018, vol. 38, no. 4, pp. 1164-1169. 
11. Khimiya sinteza szhiganiem [Chemistry of synthesis by burning]. Ed. M. Koizumi. Translated from Japanese. Moscow, Mir Publ., 1998. $247 \mathrm{p}$.

12. Jinming Jiang, Song Wang, Wei Li, Zhaohui Chen. Low-temperature synthesis of tantalum carbide by facile one-pot reaction. $\mathrm{Ce}$ ramics International, 2016, vol. 42, no. 6, pp. 7118-7124.

13. Schweiter C., Schmidt R. Physical Mechanisms of Generation and Deactivation of Singlet Oxygen. Chemical Review, 2003, vol. 103 (5), pp. 1685-1787.

14. Harneet Kaur Sidana, Rameez Ahmad Mir, O.P. Pandey. Synthesis of molybdenum nitride $\left(\mathrm{Mo}_{2} \mathrm{~N}\right)$ nanoflakes via in-situ reduction-nitridation. Journal of Alloys and Compounds, 2018, no. 736 , pp. 255-265.

15. Hae-Min Lee, Gyoung Hwa Jeong, Sang-Wook Kim, Chang-Koo Kim. Low-temperature direct synthesis of mesoporous vanadium nitrides for electrochemical capacitors. Applied Surface Science, 2017, no. 400, pp. 194-199.

16. Thobeka Kente, Sabelo Dalton Mhlanga. Gallium nitride nanostructures: Synthesis, characterization and applications. Journal of Crystal Growth, 2016, no. 444, pp. 55-72.

17. Kovba L.M., Trunov V.K. Rentgenofazovy analiz [X-ray diffraction analysis]. Moscow, MGU Publ., 1976. 232 p.

18. Zarko V.E., Gromov A.A. Energetic nanomaterials: Synthesis, Characterization and Application. Wiley- $\mathrm{VCH}$, Weincheim, 2016. $374 \mathrm{p}$.

19. Liang Tiana, Junyi Lia, Feng Lianga, Junkai Wanga, Saisai Lia, Haijun Zhanga, Shaowei Zhang. Molten salt synthesis of tetragonal carbon nitride hollow tubes and their application for removal of pollutants from wastewater. Applied Catalysis B: Environmental, 2018, no. 225, pp. 307-313.
20. Kudyakova V.S., Shishkin R.A., Elagin A.A., Baranov M.V., Beketov A.R. Aluminium nitride cubic modifications synthesis methods and its features. Review. Journal of the European Ceramic Society, 2017, no. 37, pp. 1143-1156.

21. Liang liang Lin, Starostin S.A., Qi Wanga, Hessel V. An atmospheric pressure microplasma process for continuous synthesis of titanium nitride nanoparticles. Chemical Engineering Journal, 2017, no. 321, pp. 447-457.

22. Huimin Shi, Hang Zhang, Zhi Chena, Tao Wang, Lei Wang, Wei Zeng, Guanhua Zhang, Huigao Duan. Synthesis of TiN nanostructures by $\mathrm{Mg}$-assisted nitriding $\mathrm{TiO}_{2}$ in $\mathrm{N}_{2}$ for lithium ion storage. Chemical Engineering Journal, 2018, no. 336, pp. 12-19.

23. Da Silva W.M., Ribeiro H., Ferreira T.H., Ladeira L.O., Sousa E.M.B. Synthesis of boron nitride nanostructures from catalyst of iron compounds via thermal chemical vapor deposition technique. Physica E, 2017, no. 89, pp. 177-182.

24. Kyungju Nam, Kicheol Hong, Hyeji Park, Heeman Choe. Facile synthesis of powder-based processing of porous aluminum nitride. School of Materials Science and Engineering, Kookmin University, Republic of Korea. Journal of the European Ceramic Society, April 2018, vol. 38, Iss. 4, pp. 1164-1169.

25. Ognjanovic S.M., Winterer M. Optimizing particle characteristics of nanocrystalline aluminum nitride. Powder Technology, 15 February 2018, vol. 326, pp. 488-497.

26. Uendlandt U. Termicheskie metody analiza [Thermal analysis methods]. Moscow, Mir Publ., 1978. 218 p.

27. Gromov A.A., Khabas T.A., Ilin A.P. Gorenie nanoporoshkov metallov [Metal nanopowder burning]. Ed. by A.A. Gromov. Tomsk, Deltoplan Publ., 2008. 382 p.

Received: 18 June 2018.

\section{Information about the authors}

Alexandra O. Chudinova, postgraduate student, National Research Tomsk Polytechnic University.

Alexander P. Ilyin, Dr. Sc., professor, National Research Tomsk Polytechnic University.

Lyudmila O. Root, Cand. Sc., associate professor, National Research Tomsk Polytechnic University.

Andrey V. Mostovshchikov, Cand. Sc., research fellow, associate professor, National Research Tomsk Polytechnic University.

Sofia V. Spesivtseva, master, National Research Tomsk Polytechnic University.

Jin Chun Kim, PhD technical, professor, University of Ulsan. 